\title{
Choroidal thickness in obese women
}

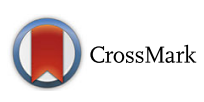

\author{
Erhan Yumusak ${ }^{1 *}$, Kemal Ornek ${ }^{1}$, Senay Arıkan Durmaz ${ }^{2}$, Aydin Cifci $^{3}$, Hatice Ayhan Guler ${ }^{1}$ and Zehra Bacanli ${ }^{3}$
}

\begin{abstract}
Background: Excessive weight is a well-known risk factor for microvascular diseases. Changes in thickness in a vascular tissue, such as the choroid, can be useful to evaluate the effect of obesity on the microvascular system. The aim of this study was to evaluate the choroidal thickness (CT) changes in obese women, using optical coherence tomography $(\mathrm{OCT})$.

Methods: The prospective clinical study included examination of the right eyes of 72 patients. The right eyes of 68 patients were examined and served as the controls. A complete ophthalmological examination and OCT imaging were performed for each group studied. The CT in each eye was measured using OCT.

Results: The obese group consisted of 72 female patients with a mean age of $37.27 \pm 1.18$ years. The control group included 68 female subjects with a mean age of $37.85 \pm 7.98$ years $(p>0.05)$. There was no statistical significant difference for the foveal retinal thickness measurements between the two groups $(p>0.5)$. Our study revealed significant choroidal tissue thickening subfoveally and at areas $500 \mu \mathrm{m}$ temporal, $500 \mu \mathrm{m}$ nasal, and $1500 \mu \mathrm{m}$ nasal to the fovea in the obese group (all $p<0.05$ ). There was a positive correlation between body mass index (BMI) and CT changes.
\end{abstract}

Conclusions: CT may increase in obese women and a positive correlation was found between BMI and CT. The trial protocol was approved by the Local Ethical Committee of the Kirıkkale University, date of registration: April 27, 2015 (registration number: 10/11).

Keywords: Choroidal thickness, Obese women, Optical coherence tomography

\section{Background}

Obesity is a common health problem and its prevalence is increasing worldwide [1-3]. Excessive weight is a wellknown risk factor for diabetes, hypertension, dyslipidemia, and microvascular diseases [4-6], including retinal vasculature $[7,8]$. One of the main concerns with obesity is that microvascular alterations cannot be diagnosed in the early stages. Although many studies have investigated the comorbidities associated with obesity [9-11], predicting the risk of developing vascular damage remains challenging.

The association of obesity with cataract formation, glaucoma, and age-related macular degeneration has been shown in varying degrees. Researchers have hypothesized that retinal microvascular changes are precursors to developing obesity based on experimental and clinical observations $[12,13]$. In the Blue Mountains Eye Study, retinal

\footnotetext{
* Correspondence: erhanyumusak@yahoo.com

${ }^{1}$ Department of Ophthalmology, Kırıkkale University, School of Medicine, Kırıkkale, Turkey

Full list of author information is available at the end of the article
}

vessel diameter was associated with the prevalence of higher body mass index (BMI) and the increased risk of incident obesity [14].

In the eye, the choroid, the posterior portion of the uveal tract, nourishes the outer portion of the retina. It contributes to the blood supplied to the prelaminar portion of the optic nerve [1], is an integral constituent in the functioning of the eye, and is involved in important diseases affecting the optic nerve, retinal pigment epithelium, and the retina. By using enhanced depth imaging optical coherence tomography (EDI-OCT), choroid images can be obtained and the choroidal thickness (CT) can be measured [3].

Previous studies have suggested that a higher BMI can trigger structural changes in the retinal vascular system that could provoke retinal dysfunction, as shown in aged-related macular degeneration or diabetic retinopathy. Therefore, knowledge of the thickness changes in a vascular tissue, such as the choroid, may help to evaluate the effect of obesity on the microvascular system. 
The prevalence of obesity among men and women varies greatly within, and between countries, with more obesity found in women than in men. This gender disparity in obese population is exacerbated among women in developing countries. In the TURDEP study, which investigated 24,788 people $>20$ years old in Turkey, the prevalence of obesity in women was 29.9 , and $12.9 \%$ in men [15].

Therefore, in the present study, we hypothesized that obesity is correlated with CT changes, particularly in women. To the best of our knowledge, this is the first study evaluating $\mathrm{CT}$ in obese female patients.

\section{Methods}

This prospective clinical study included the examination of the right eyes of 72 patients. In total, 68 right eyes of 68 patients were examined and served as controls. The study was conducted between 2015 and 2016 in accordance with the tenets of the Declaration of Helsinki. The trial protocol was approved by the Local Ethical Committee of the University of Kirıkkale. Registration of the trial was requested on April 27th, 2015 (decision no:10/11). All patients and control subjects voluntarily participated in the study and signed an informed consent form. The obese group was classified according to the World Health Organisation criteria; (BMI 18.5-24.9 kg/m² = normal; $25.0-29.9 \mathrm{~kg} / \mathrm{m}^{2}=$ pre-obese $/$ overweight, and $\geq 30.0 \mathrm{~kg} /$ $\mathrm{m}^{2}=$ obese).

In the study, the obese group included patients who had a $\mathrm{BMI}>30 \mathrm{~kg} / \mathrm{m}^{2}$, without any other disease, whereas healthy adults with BMI $<25 \mathrm{~kg} / \mathrm{m}^{2}$ constituted the control group. Obese patients were randomly selected from those monitored by the Department of Endocrinology. The exclusion criteria were as follows: a previous systemic or chronic disease such as hypertension, smoking, ocular surgery in one or both eyes; axial length $>24 \pm 1.0 \mathrm{~mm}$; and a refractive measurement $>2.0$ diopters.

All participants underwent a complete ocular examination, including a best-corrected visual acuity measurement, slit-lamp examination, intraocular pressure measurement, and dilated fundoscopy. Only the right eyes of each of the patients were selected to avoid any intra-individual bias.

The CT was measured as close to noon as possible to avoid diurnal variations. The measurements were performed using anEDI-OCT scanning system (OCT Advance Nidek RS-3000; Nidek Co. Ltd., Gamagori, Japan). Prior to evaluation using EDI-OCT scanning, the central macular thickness was measured in the right eye of each patient. Choroidal and scleral boundaries were drawn with the assistance of software programs. The boundaries limited the Bruch membrane, between the subfoveal points (FCT), to 500 and $1500 \mu \mathrm{m}$ in the nasal regions (N500, N1500) and 500 and $1500 \mu \mathrm{m}$ in the temporal regions (T500, T1500), for CT measurements. All measurements including the demarcation of the choroid and sclera were made by two independent (masked) observers. There were no significant differences between the results of the two observers $(p=0.317$ : Paired $t$-test, $r=0.716$ and $p$ 0.001:Pearson's correlation), and the average of the two results was used in our analyses.

Statistical analyses were performed using the SSPS statistical software (SPSS for Windows 23.0, Inc., Chicago, USA). The results of the descriptive analysis were provided in numbers, percentages, mean, median, and standard deviations. A paired $t$-test was used to assess the difference in the means of the observers' measurements to test the repeatability and accuracy of the two independent measurements. The independent $t$-test was used to compare the variables between the obese group and the control group, and correlations were performed using Pearson's correlation coefficient. A multiple linear regression analysis (forward) was used to determine confounding factors among the variables. $p<0.05$ was considered statistically significant.

\section{Results}

The study group consisted of 140 female (100 \%) subjects, with a mean age of $37.55 \pm 1.01$ years (median:38; range:21-59 years). There were 72 patients in the obese group, with a mean age of $37.27 \pm 1.18$ years (median: 38.5; range 21-59 years). The control group included 68 subjects, with a mean age of $37.85 \pm 7.98$ years (median:38; range 24-54 years). There was no significant difference, in terms of age, between the two groups $(p>0.5)$. Demographics of the study groups are shown in Table 1.

There was no significant difference found for foveal retinal thickness (FT) when the two groups were compared $(p>0.5)$. In contrast, the CT revealed significant differences at FCT, T500, N500, and N1500 between the two groups (all $p<0.05$ ). Changes in both FT and CT are demonstrated in Table 2.

There was a positive correlation found between BMI and CT at FCT, T500, and N500 (Table 3). Multiple linear regression analysis revealed that $\mathrm{CT}$ had been affected by BMI independently from the aspect of age of the patient (Table 4).

Table 1 Demographics of the groups

\begin{tabular}{lllll}
\hline Group & Age & BMI $\left(\mathrm{Kg} / \mathrm{m}^{2}\right)$ & Weight $(\mathrm{kg})$ & Height $(\mathrm{cm})$ \\
\hline $1(N=72)$ & $37.27 \pm 11.81$ & $39.16 \pm 6.88$ & $100.63 \pm 16.49$ & $160.42 \pm 6.20$ \\
$2(N=68)$ & $37,85 \pm 7.98$ & $21.95 \pm 59$ & $58.97 \pm 16.49$ & $168.36 \pm 4.94$ \\
& $P=0.738$ & $P<0.001$ & $P=0.004$ & $P<0.001$ \\
\hline
\end{tabular}

$B M I$ body mass index 
Table 2 Changes in foveal thickness and choroidal thickness

\begin{tabular}{lllllll}
\hline Group & Group & FCT & T500 & T1500 & N500 & N1500 \\
\hline $1(N=72)$ & $250.1 \pm 19.8$ & $349.2 \pm 58.7$ & $346.5 \pm 55.1$ & $335.8 \pm 55.1$ & $345.5 \pm 59.7$ & $327.0 \pm 55.3$ \\
$2(N=68)$ & $256.0 \pm 18.9$ & $322.7 \pm 37.8$ & $317.3 \pm 39.7$ & $313.6 \pm 39.7$ & $323.3 \pm 39.5$ & $322.2 \pm 37.7$ \\
& $P=0.185$ & $P=0.002$ & $P=0.014$ & $P=0.230$ & $P<0.001$ & $P<0.001$ \\
\hline
\end{tabular}

FCT: choroidal thickness at fovea; N500, choroidal thickness at $500 \mu \mathrm{m}$ nasal to the fovea; N1500, choroidal thickness at $1500 \mu \mathrm{m}$ nasal to the fovea; T500, choroidal thickness at $500 \mu \mathrm{m}$ temporal to the fovea; T1500, choroidal thickness at $1500 \mu \mathrm{m}$ temporal to the fovea; FT: central macular thickness

\section{Discussion}

In the eye, CT may be affected by several factors, such as age, axial length, and refractive errors [16, 17]. Diurnal changes in CT have also been reported [18]. It is believed that systemic blood pressure and intraocular pressure induce choroidal tissue changes through an autoregulatory mechanism [19]. Therefore, because the choroid possesses a rich vascular structure, all of the aforementioned factors have the potential to alter the CT [20].

A study by Tanabe et al., demonstrated a significant correlation between choroidal vein diameter and the CT [21]. Another investigation by Vance et al., reported that phosphodiesterase- 5 inhibitors, such as sildenafil citrate, increased CT via a smooth muscle relaxation effect [22]. In a study by Wong et al., CT was found to be thicker in hypercholesterolemic patients [23]. This study had a crosssectional design with only Chinese subjects; therefore, their results may not address the issue of any ethnic differences in CT. It is of interest that Regatieri et al., found that the choroid was thinner among subjects with diabetic retinopathy [24]. However, a previously observed inverse correlation between age and $\mathrm{CT}$ might have affected this correlation [25]. A number of studies have found that CT plays a prognostic or predictive role in various local (for example, diabetic retinopathy, and AMD), and systemic diseases (for example, hypertension, anemia, and rheumatoid arthritis) [24, 26-33].

Jongh et al., reported the effects of obesity on the microvascular system; hyperinsulinemia and elevated blood pressure were found to be the major causes of the vascular alterations in obese women [4]. In another study by Kawasaki et al., both retinal venous and arterial dilatation were found in hypertensive patients [7]. Research by Saito et al., studied the retinal venous system in 900 subjects and reported an incidence of 5 years of obesity in some patients [34]. The authors found a positive correlation between

Table 3 The Pearson Correlation analysis between body mass index - Choroidal thickness and foveal thickness

\begin{tabular}{|c|c|c|c|c|c|c|}
\hline AGE & $\mathrm{FCT}$ & N500 & N1500 & T500 & T1500 & FT \\
\hline$r=0.125$ & $r=0.198$ & $r=0.193$ & $r=0.082$ & $r=0.206$ & $r=0.151$ & $r=-0.162$ \\
\hline$P=0.140$ & $P=0.019$ & $P=0.022$ & $P=0.334$ & $P=0.015$ & $P=0.076$ & $P=0.056$ \\
\hline
\end{tabular}

vessel caliber and BMI; however, no correlation was shown between these changes and the development of obesity.

In this study, CT was found to be significantly reduced in the non-obese controls, except for the temporal measurement of $1500 \mu \mathrm{m}$. It was an interesting finding because as shown in recent studies, we expected a subfoveal or temporal change in CT. Previous studies reported that the macula demonstrated a thin choroid layer in the nasal region $[35,36]$. Another possibility for this regional difference may be a result of the developmental pattern of the eye.

In the light of previous reports, we hypothesized that there is a relationship between obesity and the choroidal layer of the eye. In the present study, the obesity group consisted of patients with a BMI $>30$, and subjects with a $\mathrm{BMI}<25$ constituted the control group. To avoid any diurnal effect, we performed all the measurements at noon for each patient. We also excluded patients with a history of local and systemic diseases. Although no significant differences were found for FT between the groups, there was a significant increase in $\mathrm{CT}$ at certain points (CFT, nasal 500, and $1500 \mu \mathrm{m}$, and temporal $500 \mu \mathrm{m})$ in the obese group. The results indicated that there was a positive correlation between BMI and CT, and multiple linear regression analysis revealed that $\mathrm{CT}$ was independently affected by the age of the patients.

Table 4 Multiple linear regression analysis between choroidal thickness, age and Body mass index

\begin{tabular}{llll}
\hline & & Beta $(\beta)$ & $P$ \\
\hline N500 & BMl & 0.233 & 0.004 \\
& Age & -0.317 & $<0.001$ \\
& BMl & 0.249 & 0.011 \\
T500 & Age & -0.325 & 0.012 \\
& BMl & -0.402 & 0.001 \\
T1500 & Age & -0.289 & $<0.001$ \\
& BMl & 0.204 & 0.009 \\
FCT & age & -0.423 & $<0.001$ \\
& BMl & 0.243 & 0.002 \\
& Age & -0.364 & $<0.001$ \\
\hline
\end{tabular}

FCT: choroidal thickness at fovea; N500, choroidal thickness at $500 \mu \mathrm{m}$ nasal to the fovea; N1500, choroidal thickness at $1500 \mu \mathrm{m}$ nasal to the fovea; T500, choroidal thickness at $500 \mu \mathrm{m}$ temporal to the fovea; T1500, choroidal thickness at $1500 \mu \mathrm{m}$ temporal to the fovea; BMI: Body mass index 
There were some limitations in the study, such as the pathogenesis of obesity, which included several unknown hormonal and genetic factors; moreover, because choroid is a vascular tissue, it may be affected by local and systemic factors. We also excluded patients with systemic metabolic disorders to avoid confounding factors. A further limitation of the study was the lack of data on CT changes after weight loss through dietary restriction. The prevalence of obesity among women is greater than that in men, which we found to be the same for the patients in our Department of Endocrinology. Due to the difficulty in making homogenous groups of obese patients of both genders and the fact that choroidal tissue may be different in both genders, we decided to include only females in our study. Indeed, it may be proposed that obese male patients also have choroidal changes; therefore, further studies with male patients are warranted in the future.

\section{Conclusion}

In summary, our data provides evidence for a relationship between CT and obesity in female patients. Vascular abnormalities may occur at early stages in obesity and ocular circulation may be a preferred target for the disease process. The assessment of CT is a quick and noninvasive technique, which can be utilized to determine such abnormalities. Meanwhile, it is unclear how this data may be applied to individual patients and how it can benefit obesity management. The data suggests that CT measurement has a predictive role and BMI should be included among the parameters that may affect $\mathrm{CT}$ results in obese women. A prospective follow-up study with a large sample size is required to test our hypothesis and to verify the results of the present clinical study.

\section{Ethics approval and consent to participate}

The study protocol was approved by the Institutional Review Board (Local Ethical Committee of the Kurlkkale University), and informed written consent was obtained from all participants. The design of the study followed the tenets of the Declaration of Helsinki for biomedical research.

\section{Consent to publish}

All authors have given consent to the publication for this manuscript.

\section{Availability of data and materials}

In this study data supporting findings can be found in Kırkkkale University, School of Medicine, Department of Ophthalmology, Dr Erhan Yumusak; Mail: Erhany umusak@yahoo.com.

\section{Abbrevations}

BMl: body mass index; $\mathrm{CT}$ : choroidal thickness; EDI-OCT: enhanced-depth imaging optical coherence tomography; FCT: choroidal thickness at fovea;
FT: foveal thickness (Central macular thickness); N1500: choroidal thickness at $1500 \mu \mathrm{m}$ nasal to the fovea; N500: choroidal thickness at $500 \mu \mathrm{m}$ nasal to the fovea; RPE: retinal pigment epithelium; T1500: choroidal thickness at $1500 \mu \mathrm{m}$ temporal to the fovea; T500: choroidal thickness at $500 \mu \mathrm{m}$ temporal to the fovea.

\section{Competing interest}

The authors declare no competing interests.

\section{Authors' contributions}

$E Y$ is the first author of this article. Designed the study: SAD, EY, AC. Preparation of ethics forms and apply: ZB. Manuscript preparation, analysis interpretation of data: EY. Contributed reagents/materials/analysis tools: EY,SAD. Wrote the paper: EY, KO. Reviewed of the manuscript: KO, EY. Collected and entered the data: EY, SAD, ZB, HAG. All authors read and approved the final manuscript.

\section{Acknowledgements}

This study was not supported by any funding project.

\section{Funding}

No funding was obtained in this study.

\section{Author details}

${ }^{1}$ Department of Ophthalmology, Kırıkkale University, School of Medicine, Kırıkkale, Turkey. ${ }^{2}$ Department of Endocrinology, Kırıkkale University, School of Medicine, Kırıkkale, Turkey. ${ }^{3}$ Department of Internal Medicine, Kırıkkale University School of Medicine, Kırıkkale, Turkey.

Received: 16 February 2016 Accepted: 28 April 2016

Published online: 04 May 2016

\section{References}

1. Berghöfer A, Pischon T, Reinhold T, Apovian CM, Sharma AM, Willich SN. Obesity prevalence from a European perspective: a systematic review. BMC Public Health. 2008;8:200.

2. Flegal KM, Carroll MD, Kit BK, Ogden CL. Prevalence and trends in obesity among US adults, 1999-2000. JAMA. 2002;288:1723-7.

3. Must A, Spadano J, Coakley EH, Field AE, Colditz G, Dietz WH. The disease burden associated with overweight and obesity. JAMA. 1999;282:1523-9.

4. de Jongh RT, Serné EH, IJzerman RG, de Vries G, Stehouwer CD. Impaired microvascular function in obesity: implications for obesityassociated microangiopathy, hypertension, and insulin resistance. Circulation. 2004;109:2529-35.

5. de Jongh RT, Serné EH, IJzerman RG, Jørstad HT, Stehouwer CD. Impaired local microvascular vasodilatory effects of insulin and reduced skin microvascular vasomotion in obese women. Microvasc Res. 2008;75:256-62.

6. Jonk AM, Houben AJ, de Jongh RT, Serné EH, Schaper NC, Stehouwer CD. Microvascular dysfunction in obesity: a potential mechanism in the pathogenesis of obesity-associated insulin resistance and hypertension. Physiology (Bethesda). 2007;22:252-60.

7. Kawasaki R, Tielsch JM, Wang JJ, Wong TY, Mitchell P, Tano Y, Tominaga M, Oizumi T, Daimon M, Kato T, Kawata S, Kayama T, Yamashita $\mathrm{H}$. The metabolic syndrome and retinal microvascular signs in a Japanese population: the Funagata study. Br J Ophthalmol. 2008; 92:161-6.

8. Wong TY, Duncan BB, Golden SH, Klein R, Couper DJ, Klein BE, et al. Associations between the metabolic syndrome and retinal microvascular signs: the Atherosclerosis Risk In Communities study. Invest Ophthalmol Vis Sci. 2004;45:2949-54

9. Snyder EE, Walts B, Pérusse L, Chagnon YC, Weisnagel SJ, Rankinen T, Bouchard C. The human obesity genemmap: the 2003 update. Obes Res. 2004;12:369-439.

10. Tataranni PA, Harper IT, Snitker S, Del Parigi A, Vozarova B, Bunt J, Bogardus C, Ravussin E. Body weight gain in free-living Pima Indians: effect of energy intake vs expenditure. Int J Obes Relat Metab Disord. 2003;27:1578-83.

11. Zurlo F, Ferraro RT, Fontvielle AM, Rising R, Bogardus C, Ravussin E. Spontaneous physical activity and obesity: cross-sectional and longitudinal studies in Pima Indians. Am J Physiol. 1992;263:E296-300. 
12. Hayashi K, Kanda T, Homma K, Tokuyama H, Okubo K, Takamatsu I, Tatematsu S, Kumagai $H$, Saruta T. Altered renal microvascular response in Zucker obese rats. Metabolism. 2002;51:1553-61.

13. Ikram MK, de Jong FJ, Vingerling JR, Witteman JC, Hofman A, Breteler MM, et al. Are retinal arteriolar or venular diameters associated with markers for cardiovascular disorders? The Rotterdam StudyInvest Ophthalmol Vis Sci. 2004;45:2129-34

14. Wang JJ, Taylor B, Wong TY, Chua B, Rochtchina E, Klein R, Mitchell P. Retinal vessel diameters and obesity: a population-based study in older persons. Obesity. 2006;14:206-14.

15. Satman I, Yilmaz T, Sengül A, Salman S, Salman F, Uygur S, et al. Population-based study of diabetes and risk characteristics in Turkey: results of the turkish diabetes epidemiology study (TURDEP). Diabetes Care. 2002;25(9):1551-6.

16. Ikuno Y, Kawaguchi K, Nouchi T, Yasuno Y. Choroidal thickness in healthy Japanese subjects. Invest Ophthalmol Vis Sci. 2010;51:2173-6.

17. Agawa T, Miura M, Ikuno Y, Makita S, Fabritius T, Iwasaki T, et al. Choroidal thickness measurement in healthy Japanese subjects by three-dimensional high-penetration optical coherence tomography. Graefes Arch Clin Exp Ophthalmol. 2011;249(10):1485-92.

18. Brown JS, Flitcroft DI, Ying GS, Francis EL, Schmid GF, Quinn GE, et al. In vivo human choroidal thickness measurements: evidence for diurnal fluctuations. Invest Ophthalmol Vis Sci. 2009;50:5-1236.

19. Reiner A, Li C, Del Mar N, Fitzgerald ME. Choroidal blood flow compensation in rats for arterial blood pressure decreases is neuronal nitric oxide-dependent but compensation for arterial blood pressure increases is not. Exp Eye Res. 2010;90:734-74137.

20. Kiel JW. Choroidal myogenic autoregulation and intraocular pressure. Exp Eye Res. 1994;58:529-43.

21. Tanabe H, Ito Y, Iguchi Y, Ozawa S, Ishikawa K, Terasaki H. Correlation between cross-sectional shape of choroidal veins and choroidal thickness. Jpn J Ophthalmol. 2011;55:614-9.

22. Vance SK, Imamura Y, Freund KB. The effects of sildenafil citrate on choroidal thickness as determined by enhanced depth imaging optical coherence tomography. Retina. 2011;31:332-5.

23. Wong IY, Wong RL, Zhao $\mathrm{P}$, Lai WW. Choroidal thickness in relation to hypercholesterolemia on enhanced depth imaging optical coherence tomography. Retina. 2013;33(2):423-8.

24. Regatieri CV, Branchini L, Carmody J, Fujimoto JG, Duker JS. Choroidal thickness in patients with diabetic retinopathy analyzed by spectral-domain optical coherence tomography. Retina. 2012;32:563-8.

25. Ding X, Li J, Zeng J, Ma W, Liu R, Li T, et al. Choroidal thickness in healthy Chinese subjects. Invest Ophthalmol Vis Sci. 2011;52:9555-60.

26. Yiu G, Chiu SJ, Petrou PA, Stinnett S, Sarin N, Farsiu S, et al. Relationship of central choroidal thickness with age-related macular degeneration status. Am J Ophthalmol. 2015;159(4):617-26.

27. Sanchez-Cano A, Orduna E, Segura F, Lopez C, Cuenca N, Abecia E, Pinilla I. Choroidal thickness and volume in healthy young white adults and the relationships between the mand axial length, ammetropy and sex. Am J Ophthalmol. 2014;158(3):574-83.

28. Akay F, Gundogan FC, Yolcu U, Toyran S, Uzun S.Choroidal thickness in systemic arterial hypertension. Eur J Ophthalmol. 2015 Sep 8:0. doi: 10.5301/ ejo.5000675. [Epub ahead of print]

29. Sizmaz S, Küçükerdönmez C, Pinarci EY, Karalezli A, Canan H, Yilmaz G. The effect of smoking on choroidal thickness measured by optical coherence tomography. Br J Ophthalmol. 2013;97:601-4.

30. Yumusak E, Ciftci A, Yalcin S, Sayan CD, Dikel NH, Ornek K. Changes in the choroidal thickness in reproductive-aged women with iron-deficiency anemia. BMC Ophthalmol. 2015:15(1):186.

31. Duru N, Altinkaynak H, Erten \$̧, Can ME, Duru Z, Uğurlu FG, Çağıl N. Thinning of Choroidal Thickness in Patients with Rheumatoid Arthritis Unrelated to Disease Activity. Ocul Immunol Inflamm. 2015;31:1-8 [Epub ahead of print].

32. Ingegnoli F, Gualtierotti R, Pierro L, Del Turco C, Miserocchi E, Schioppo T, et al. ACUTE study group. Choroidal impairment and macular thinning in patients with systemic sclerosis: The acute study. Microvasc Res. 2015;97:31-6.

33. Pekel G, Alur I, Alihanoglu YI, Yagci R, Emrecan B. Choroidal changes after cardiopulmonary bypass. Perfusion. 2014:29:560-6.

34. Saito K, Tanabe Y, Kawasaki R, Daimon M, Oizumi T, Kato T, Kawata S, Kayama T, Yamashita $\mathrm{H}$. Is retinal vasculature change associated with risk of obesity? Longitudinal cohort study in Japanese adults: The Funagata study. Jiabetes Investig. 2011;2(3):225-32.

35. Margolis R, Spaide RF. A pilot study of enhanced depth imaging optical coherence tomography of the choroid in normal eyes. Am J Ophthalmol. 2009;147(5):811-5

36. Manjunath V, Taha M, Fujimoto JG, Duker JS. Choroidal thickness in normal eyes measured using Cirrus HD optical coherence tomography. Am J Ophthalmol. 2010;150(3):325-9.

\section{Submit your next manuscript to BioMed Central and we will help you at every step:}

- We accept pre-submission inquiries

- Our selector tool helps you to find the most relevant journal

- We provide round the clock customer support

- Convenient online submission

- Thorough peer review

- Inclusion in PubMed and all major indexing services

- Maximum visibility for your research

Submit your manuscript at www.biomedcentral.com/submit
) Biomed Central 